\title{
The conjunctival allergen provocation test and the nasal allergen provocation test as specific alternatives to the oral food challenge
}

\author{
Edyta Krzych-Fatta
}

Department of the Environmental Hazards Prevention and Allergology, Faculty of Health Sciences, Medical University of Warsaw, Warsaw, Poland

Adv Dermatol Allergol 2022; XXXIX (2): 245-250

DOI: https://doi.org/10.5114/ada.2021.105362

\begin{abstract}
Provocation tests with allergens play a critical role in differential diagnosis of allergic diseases. The nasal allergen provocation test and the conjunctival allergen provocation test are particularly useful in the diagnosis of allergies with the underlying mechanism involving IgE-dependent reactions. Interestingly, the symptoms typical of both the nasal allergen provocation test and conjunctival allergen provocation test occur during the tests: ocular symptoms during the nasal test and typical nasal symptoms during the conjunctival test. These symptoms provide a picture of the early and late phases of the allergic reaction. Increasing attention is given to the role of the two provocation tests in differential diagnosis of food allergies, and the first studies involving food challenge tests provide a solid foundation for further research in this area.
\end{abstract}

Key words: food allergen, conjunctival allergen provocation test, nasal allergen provocation test.

\section{Introduction}

Allergy is referred to as a lifestyle disease on the basis of its scale. Allergic diseases affect nearly $40 \%$ of the population of Poland, with $25 \%$ of Poles suffering from allergic rhinitis and 5\% from bronchial asthma. These are followed by asthma (12\%), atopic skin inflammation (9\%), nettle rash (ranging from 2.1\% to 6.7\% in the Polish population of children) and food allergies (13\%). In terms of epidemiology, the incidence of food allergies has been growing and such allergies already affect nearly $6-8 \%$ of children and $1-2 \%$ of the adult population [1]. Moreover, a food allergy can be described as the starting point for a patient's allergic march as early as in the first years of the patient's childhood. It starts with food-related ailments and smoothly develops into atopic skin inflammation, bronchial asthma and, finally, allergic rhinitis. Another strong argument for taking measures to promote early prevention of allergic diseases is what is known as multiple morbidities [2, 3] in the area of allergic diseases. Multiple morbidities have an adverse impact on the qual- ity of the patient's life in all respects, depending on the seriousness of the ailments experienced by the patient.

The implementation of diagnostic models designed to detect allergic diseases and their widespread availability help improve the health of society at large and the efficiency of health care delivery. Clinical history taking and diagnostic tests (including skin prick tests, patch tests, slgE tests or molecular tests) play a critical role in the diagnosis of allergic diseases. In the case of food allergies, the oral food challenge (i.e. Goldman's test (an open challenge) or a modified version of the test, i.e. a placebo-controlled blind food challenge where the food is hidden) plays a critical role. Typical complaints reported by patients with positive provocation test results include (colicky) abdominal pain, diarrhoea, nausea and vomiting. In the event of the occurrence of any of the following critical symptoms, i.e. skin-related symptoms ( $\geq 3$ nettle rash bumps, angioedema, erythema, rash), respiratory symptoms (wheezing, stridor, recurring cough, voice loss) or cardiovascular symptoms (loss of consciousness, hypotension), the test has to be stopped [4]. Certain con-

Address for correspondence: Edyta Krzych-Fałta PhD, Department of the Environmental Hazards Prevention and Allergology, Faculty of Health Sciences, Medical University of Warsaw, 1a Banacha St, 02-097 Warsaw, Poland, phone: +48 225992039 , fax: +48 2259920 42, e-mail: edyta.krzych-falta@wum.edu.pl Received: 20.12.2020, accepted: 22.01.2021. 
straints of the oral food challenge, such as the fact that this test should be performed mainly under hospital conditions, the fact that its availability is limited and the fact that the techniques employed for this test lack objectivity, have a major impact on the result of the test. Conversely, given the constraints of the oral food challenge, the conjunctival allergen provocation test (CAPT) and the nasal allergen provocation test (NAPT) may serve as two alternatives to the challenge. Moreover, the oral food challenge causes symptoms typical of, in particular, the nasal provocation test, which may hypothetically be the answer to the question about the shared reaction mechanism and the role of the nasal cavity in the diagnosis of food allergies together with other conditions.

\section{The universal nature of the conjunctival allergen provocation test and the nasal allergen provocation test}

Frequently, if the discrepancy between a patient's clinical history and the results of diagnostic tests in the areas of rhinoallergology and allergology (Table 1) is considerable, allergen provocation tests are a major part of differential diagnosis and, in some cases, may determine further action in the treatment process. The main argument in favour of such tests is the identification of the factor that triggers symptoms of allergy/oversensitivity to allergens [5-8]. The results of allergen provocation tests are assessed in relation to the early and late phases of the allergic reaction. Critical significance is attached to the early phase of the allergic reaction, where the occurrence of a local shock reaction causes the release of preformed mediators of the inflammatory reaction, including kinins, tryptase and histamine, in the case of both the CAPT and the NAPT [9]. In the case of the NAPT, it seems that the first 1-30 min of the test is the critical stage, where itching occurs, with sneezing and increased serous discharges at the $2^{\text {nd }}$ and $3^{\text {rd }}$ min and swelling of the nasal mucous membrane at approx. the $10^{\text {th }} \min [5,9]$. In the CAPT, itching occurs after 3 min from the administration of an allergen, followed by conjunctival redness after $5 \mathrm{~min}$. These symptoms last for $15 \mathrm{~min}$. A small percentage (30-40\%) of the patients subjected to the NAPT show latephase reactions, such as nasal obstruction and, to a lesser degree, nasal discharges and sneezing [10].

An important aspect, which continues to be a subject of discussion, is the use of objective and subjective techniques to measure the results of provocation tests. The choice of such techniques is crucial. It is also a valuable source of information about the degree of the allergic reaction from the organ subjected to the test. In addition to the techniques specified in Table 1, the results of CAPTs are determined by examining the patient's tears, with other techniques including conjunctival biopsies and the use of confocal microscopy to examine the migration of inflammatory cells. Also, an ophthalmologist may use a slit lamp to measure the results under hospital conditions. In the case of NAPTs, it is acceptable to measure the content of reaction mediators in the nasal lavage fluid, and nasal patency can be evaluated by means of nasal endoscopy.

Table 1. Evaluation of allergen provocation tests [5-8]

\begin{tabular}{|c|c|c|c|c|}
\hline \multirow{2}{*}{$\begin{array}{l}\text { Evaluation } \\
\text { methods }\end{array}$} & \multicolumn{2}{|c|}{ Conjunctival allergen provocation test } & \multicolumn{2}{|c|}{ Nasal allergen provocation test } \\
\hline & Technique & Evaluation & Technique & Evaluation \\
\hline \multirow[t]{3}{*}{$\begin{array}{l}\text { Subjective } \\
\text { techniques }\end{array}$} & $\begin{array}{l}\text { Abelson's point- } \\
\text { based grading } \\
\text { scale }\end{array}$ & $\begin{array}{l}\text { Redness (0: none, } 1 \text { : mild. } \\
\text { 2: medium, 3: severe); } \\
\text { Tearing (0: none, 1: watery eyes, } \\
\text { 2: medium (tearing with nasal } \\
\text { discharge), 3: tears dripping); } \\
\text { Itching (0: none, } 1: \text { mild, } 2 \text { \& } \\
\text { severe) }\end{array}$ & $\begin{array}{l}\text { Visual Analogue } \\
\text { Scale (VAS) }\end{array}$ & $\begin{array}{l}\text { A horizontal 100-mm scale, where } \\
0-30 \mathrm{~mm} \text { means } \\
\text { Mild symptoms, } 31-70 \mathrm{~mm} \text { means } \\
\text { medium symptoms and } 71-100 \mathrm{~mm} \\
\text { means } \\
\text { Severe symptoms }\end{array}$ \\
\hline & $\begin{array}{l}\text { Riechelmann's } \\
\text { point-based } \\
\text { grading scale }\end{array}$ & $\begin{array}{l}\text { 1: no symptoms, } 2 \text { : itching, } \\
\text { redness, foreign body sensation; } \\
\text { 3: symptoms ( } 1 \text { point) and tearing, } \\
\text { bulbar conjunctival injection }\end{array}$ & Likert score & 0: none, 1: mild, 2: medium, 3: severe \\
\hline & & $\begin{array}{l}\text { 4: symptoms ( } 2 \text { points) and tarsal } \\
\text { conjunctiva infiltration, light } \\
\text { sensitivity; } 5 \text { : symptoms ( } 3 \text { points) } \\
\text { and conjunctival chemosis, swollen } \\
\text { eyelids }\end{array}$ & Total nasal score & $\begin{array}{l}\text { A 12-point } \\
\text { scale covering the severity points for } \\
\text { the four main symptoms: } \\
\text { rhinorrhoea, nasal congestion, } \\
\text { sneezing and nasal itching }\end{array}$ \\
\hline $\begin{array}{l}\text { Objective } \\
\text { techniques }\end{array}$ & Use of a slit lamp & $\begin{array}{l}\text { Chemosis, swelling, conjunctival } \\
\text { congestion ( } 0 \text { : none, } 1 \text { : mild, } \\
\text { 2: medium, 3: severe) }\end{array}$ & $\begin{array}{l}\text { Peak Nasal } \\
\text { Inspiratory Flow } \\
\text { (PNIF) } \\
\text { Acoustic } \\
\text { Rhinometry } \\
\text { Rhinomanometry }\end{array}$ & $\begin{array}{l}\text { Measurement of cross-sectional areas } \\
\text { of the nose } \\
\text { CSA- } 2 \geq 40 \% \\
\text { Measurement of the amount of air } \\
\text { flowing through the nose at } 150 \mathrm{~Pa}\end{array}$ \\
\hline
\end{tabular}


Table 2. Indications for and contraindications against allergen provocation tests [5-8]

\begin{tabular}{|c|c|}
\hline Conjunctival allergen provocation test & Nasal allergen provocation test \\
\hline \multicolumn{2}{|l|}{ Identification of a sensitising agent, polysensitization } \\
\hline \multicolumn{2}{|l|}{ Clinical diagnosis differences: } \\
\hline \multicolumn{2}{|c|}{$\begin{array}{l}\text { - Determination of indications for immunotherapy, determination of allergens directly responsible for the patient's symptoms } \\
\text { and the use of this determination to decide on the ingredients of a vaccine and monitoring the effects of desensitisation and } \\
\text { pharmacotherapy }\end{array}$} \\
\hline \multicolumn{2}{|c|}{ - Scientific purposes (studying the mechanisms of allergic reactions and of the impact of various agents on such reactions) } \\
\hline - Occupational allergies (e.g. An allergy to latex) & $\begin{array}{l}\text { - Diagnosis of persistent rhinitis, chronic rhinitis or occupational } \\
\text { rhinitis (a likelihood of asthma) and local allergic rhinitis }\end{array}$ \\
\hline \multicolumn{2}{|l|}{ - Differential diagnosis of ocular symptoms } \\
\hline \multicolumn{2}{|l|}{ - Diagnosis of a food allergy* } \\
\hline \multicolumn{2}{|l|}{ Contraindications against allergen provocation tests } \\
\hline \multicolumn{2}{|l|}{ Absolute contraindications } \\
\hline \multicolumn{2}{|l|}{ A past anaphylactic reaction } \\
\hline \multicolumn{2}{|c|}{$\begin{array}{l}\text { A contraindication against administration of adrenaline, treatment with } \beta \text {-adrenolytic drugs } \\
\text { (ACE) inhibitors } \\
\text { No access to the medication and equipment necessary to respond to anaphylactic shocks }\end{array}$} \\
\hline \multicolumn{2}{|c|}{$\begin{array}{l}\text { An active condition affecting the organ to be subjected to the test (rhinitis, conjunctivitis, food allergy*, oversensitivity to } \\
\text { medication, allergy to hymenoptera venoms), uncontrolled bronchial asthma and other diseases }\end{array}$} \\
\hline \multicolumn{2}{|l|}{ Unstable ischemic heart disease and severe circulatory failure } \\
\hline \multicolumn{2}{|l|}{ Pregnancy and lactation } \\
\hline \multicolumn{2}{|l|}{ Pollen seasons } \\
\hline Other eye diseases & - Systemic immunotherapy \\
\hline \multirow[t]{11}{*}{ Eye surgery within the last 6 months } & - Other systemic diseases \\
\hline & Relative contraindications \\
\hline & Age under 5 years \\
\hline & Unavailability of standardised allergen extracts \\
\hline & $\begin{array}{l}\text { Nasal deformation and anatomical defects (choanal atresia, nasal } \\
\text { septum perforation, a considerable curvature of the nasal septum) }\end{array}$ \\
\hline & - Nasal polyps and atrophic rhinitis, adenoid hypertrophy \\
\hline & Temporary contraindications \\
\hline & Vaccination (1 week) \\
\hline & -A severe bacterial or virus infection of the airways (4 weeks) \\
\hline & Nasal surgery and nasal sinus surgery (6-8 weeks) \\
\hline & $\begin{array}{l}\text { - Drinking alcohol and/or smoking within } 24-48 \mathrm{~h} \text { before the NAPT, } \\
\text { eating spicy food and/or drinking coffee }\end{array}$ \\
\hline \multicolumn{2}{|l|}{ Pharmacological preparation for the test } \\
\hline $\begin{array}{l}\text { Stop taking the following local medications: antihistamines } \\
\text { ( } 3 \text { days-4 weeks), mast cell stabilisers (three } 24 \text {-hour periods), } \\
\text { glucocorticoids (1-4 weeks), non-steroidal anti-inflammatory } \\
\text { drugs ( } 7 \text { days), cyclosporine A ( } 7 \text { months) } \\
\text { The following systemic medications: antihistamines ( } 5 \text { days } \\
-4 \text { weeks), glucocorticoids ( } 2-4 \text { weeks), antileukotrienes } \\
\text { ( } 21 \text { days) }\end{array}$ & $\begin{array}{l}\text { Stop taking the following local medications: antihistamines } \\
\text { (two 24-hour periods), mast cell stabilisers (two } 24 \text {-hour periods), } \\
\text { glucocorticoids (two } 24 \text {-hour periods), ophthalmic non-steroidal anti- } \\
\text { inflammatory drugs ( } 7 \text { days), ophthalmic cyclosporine A ( } 7 \text { days) } \\
\text { The following systemic medications: antihistamines ( } 7 \text { days), } \\
\text { glucocorticoids (14 days), antileukotrienes ( } 21 \text { days) }\end{array}$ \\
\hline
\end{tabular}

Both the CAPT and the NAPT are generally considered to be safe methods $[6,8]$. It is, however, not less important to take into account the absolute and relative contraindications (Table 2 ) and to follow the test protocol(s) (Table 3) in the selection of patients for the tests. It is also important to keep the patient under observation for at least $30 \mathrm{~min}$ to be able to respond to any adverse effects that may occur some time after the 
Table 3. Provocation test protocols $[6,7]$

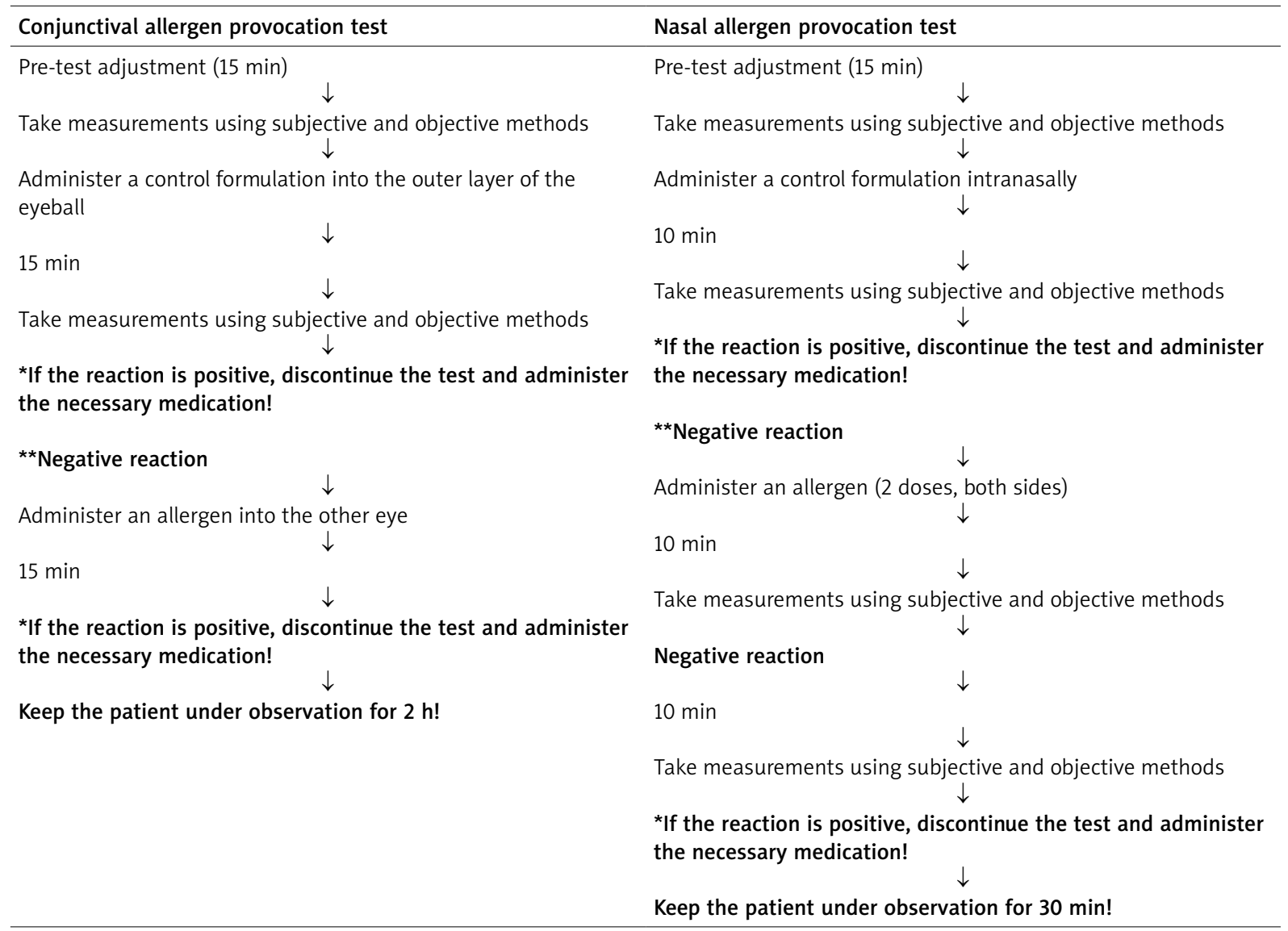

test, particularly for patients with bronchial asthma as a co-occurring condition, by monitoring the function of the patient's lower respiratory tract (the use of spirometry is recommended as is the measurement of the level of nitrogen oxide in the air exhaled). Early-phase complications include itching and swelling of the nasal part of the pharynx, eustachian tube obstruction (a feeling of blocked ears), sinusitis, conjunctivitis, laryngeal symptoms, cough, bronchoconstriction and, although hypothetically extremely rare, systemic anaphylactic reactions (nettle rash or anaphylactic shock). In contrast, the symptoms that may occur in the late phase of the allergic reaction include nasal and bronchial symptoms, i.e. swelling of the mucous membrane of the nose, bronchial hyperresponsiveness and bronchoconstriction.

Provocation tests may be performed through either titration or administration of only one dose of an allergen, depending on the purpose of the test, i.e. diagnosis or research. The use of titration, where an allergen is administered in increasing doses, carries the potential risk of adverse symptoms occurring as a result of combining allergen doses in both the CAPT and the NAPT. The allergen doses for use in a titration test should be prepared under laboratory conditions in accordance with the enclosed test protocol (e.g. in SBU/ml, the first dose could be $5 \mathrm{SBU} / \mathrm{ml}$, followed by $50 \mathrm{SBU} / \mathrm{ml}, 160 \mathrm{SBU} /$ $\mathrm{ml}, 500 \mathrm{SBU} / \mathrm{ml}, 1,600 \mathrm{SBU} / \mathrm{ml}$ and $5,000 \mathrm{SBU} / \mathrm{ml}$; or $1: 1000,1: 100$ and $1: 10$ solutions). A single dose is the one that triggers the threshold reaction, e.g. 5,000 $\mathrm{SBU} / \mathrm{ml}$. It is administered intranasally into the region of the head of the inferior nasal concha in the NAPT. In the CAPT, the allergen should be administered into the conjunctival sac of the eye (the inferior temporal quadrant: 1 drop, $20 \mu l)$. The allergens for provocation tests should be standardised allergens (with the right pH value being neutral and with the acceptable units being: SQ-U/ml, $\mathrm{SBU} / \mathrm{ml}, \mathrm{AU} / \mathrm{ml}, \mathrm{HEP} / \mathrm{ml}$ or $\mathrm{w} / \mathrm{v} \%$ (allergen levels and responses are expressed: in standardized biological units, protein nitrogen; by weight - by volume). They should be stored at a temperature of $4^{\circ} \mathrm{C}$ (and heated to room temperature before they are administered). In the case of the NAPT, two doses of the allergen ( $0.05 \mathrm{ml}$ per dose) should be administered into both sides of the nasal cavity using the traditional method by means of an atomizer $(10 \pm 2 \%)$. In the CAPT, the allergens $(20-40 \mu \mathrm{l})$ should be administered by means of a laboratory pipette for dos- 
age accuracy and precision. The recommended conditions in the room for provocation tests are a temperature of $20 \pm 1.5^{\circ} \mathrm{C}$ and a humidity of $40-60 \%$. It also important to ensure that the room is free from inhalation irritants (such as methacholine) that may affect the epithelial lining of the respiratory tract or the eyes [7, 8, 11, 12].

The results of CAPTs and NAPTs should be interpreted on the basis of all the clinical indicators used to measure the response of the challenged organs to the allergens administered in the tests.

\section{Conjunctival and nasal provocation tests with food allergens}

The nasal cavity, like the organ of sight, is a well-vascularised area and contains a large number of mast cells, which is of significance when measuring the degree of allergic reactions. Diagnostic testing for food allergies is given special attention by the experts behind the European Nasal Provocation Test Standardization Consensus; it should also be noted as an indication for CAPTs. (Clinical) studies are increasingly reported in the literature which confirm the need for the above provocation tests to be used in the case of additional categories of patients with food allergens, including patients allergic to milk, eggs and peanuts. One example is a study where a group of young children ( $N=102$ and 28 children in the control group) allergic to peanuts were subjected to CAPTs. The tests showed, quite unexpectedly, some ground-breaking results. The results of the CAPTs for 81 children with a confirmed double blind placebo oral provocation test were positive; the specificity and sensitivity levels were 0.83 and 0.96 , respectively. It needs to be noted that no adverse effects were identified in the CAPT, unlike in the oral food challenge. The study included CAPTs (titration tests: $1: 80,1: 40,1: 20,1: 10$ and $1: 1$ ) and a double blind placebo oral provocation test (allergen concentrations: 3 mg, 10 mg, 30 mg, 100 mg, 300 mg) showed no or mild general symptoms in $97 \%$ of the subjects and moderate symptoms in $3.3 \%$ and $25.7 \%$. Unlike in the oral food challenge, no severe reactions were identified in the CAPTs. Based on the results of the study, the authors estimate that the risk of moderate and severe general symptoms in the oral food challenge is nearly ten times higher compared to that for the CAPT [13]. Similarly, Kvenshagen et al. showed in a study involving 149 patients that the CAPT (using milk allergens) is a simple, reliable, highly-specific and highly-sensitive method in the diagnosis of food allergies. Moreover, the study showed a strong correlation of the positive results of the CAPTs and the degree of the food allergy identified [14].

The study should be given special attention as it meets the expectations of the experts behind nasal provocation test standardization consensuses. CAPTs and NAPTs are generally available, easy to perform and easy to measure and, as such, may potentially be the ideal pre-diagnostic tools in the selection of patients for oral food challenges. Alternatively, given their high specificity and sensitivity levels, they may replace the oral food challenge in the process of selecting subjects for subsequent stages of the treatment process. The results of CAPTs provide further evidence in support of the multidimensional nature of provocation tests. French and US researchers achieved surprising results in their study using a mouse model, in an attempt to identify differences in the response from the nasal cavity and the gastrointestinal tract to an inhaled peanut allergen. Administered orally and intranasally, the allergen caused major cellular changes involving increased slgE levels and increased responsiveness of the bronchia to the allergen inhaled by the patient [15]. Two years later, Clark et al. subjected a group of 24 children to an allergen provocation test with chicken egg allergens (versus a placebo group). They made the first attempt to assess the allergic reaction in such a test using objective techniques, namely facial thermography. The results for 13 subjects were positive. The facial temperature increased by $0.8^{\circ} \mathrm{C}$ on average (specificity: $91 \%$, sensitivity: $100 \%)$ during the first 20 min after allergen administration. There were significant differences in the measured body temperature increase values between the nasal cavity and the oral cavity. The temperature increased at the $139^{\text {th }}$ min of the test in the nasal cavity and at minute 46.1 in the oral cavity. This proves that the reaction in the nasal cavity occurs later than the reaction in the oral cavity does, the reason being that it is the oral cavity that is the first point of exposure to the allergen. Moreover, the degree of the response of the challenged organ, i.e. the temperature increase by $2.5^{\circ} \mathrm{C}$ for the nasal cavity versus $1.1^{\circ} \mathrm{C}$ for the oral cavity, confirms that undertaking further research in this area was a good decision. It was also the first study to prove the co-occurrence of reactions in the nasal cavity and the oral cavity [16]. A milestone in the search for cause-and-effect relationships for reactions in the nasal cavity to food allergens was a study conducted by Clark et al. in 2012. They used peanut allergens (10 $\mu \mathrm{g}$ of the allergen suspended in $100 \mu \mathrm{l}$ of a saline solution) and a thermograph to subject a group of 16 children to a placebo-controlled test. It was clearly the first nasal provocation test with a food allergen ever. In addition to typical reactions measured with a thermograph (the maximum increase in the nasal cavity temperature was $0.9^{\circ} \mathrm{C}$, at minute 18.2 of the test), typical nasal symptoms occurred, such as itching, watery discharges and nasal obstruction. It needs to be noted that no other symptoms from any other organs or systems were identified. The small dose of the allergen $(10 \mu \mathrm{g})$ is, the researchers stress, $1 / 1000^{\text {th }}$ of the dose administered orally and poses no risk of a systemic reaction [17]. It seems that the dose and the preparation of the allergen are crucial in food allergen provocation tests. While standardised doses are available for tests that use the com- 
mon inhalant allergens, further research in this regard is needed in this case. In the studies referred to above, the authors used ready-to-use extracts/lyophilisates. Perhaps a food allergen suspended in a saline solution (at an appropriate concentration and administered in increasing doses) that is commonly used on a daily basis would be sufficient, except that it comes in the powder form and is free from preservatives and enhancers. The degree of the response of the mucous membrane of, for example, the nasal cavity to food allergens that cross-react with environmental allergens (e.g. peanuts cross-reacting with birch pollen) raises some questions as well. These and other questions will certainly have to be addressed in further research into the aspects discussed in this paper.

\section{Conclusions}

Conjunctival and nasal provocation tests with food allergens are undoubtedly a promising alternative in differential diagnosis of food allergies. However, given the relatively small number of studies, further studies involving representative groups of subjects are needed.

\section{Conflict of interest}

The author declares no conflict of interest.

\section{References}

1. Samoliński B, Sybilski AJ, Raciborski F, et al. Prevalence of rhinitis in Polish population according to the ECAP (Epidemiology of Allergic Discorders in Poland) study. Otolaryngol Pol 2009; 63: 324-30.

2. Raciborski F, Bousqet J, Namysłowski A, et al. Dissociating polysensitization and multimorbidity in children and adults from a Polish general population cohort. Clin Transl Allergy 2019; 9: 4

3. Bousquet J, Anto JM, Wickman M, et al. Are allergic multimorbidities and IgE polysensitization associated with the persistence or re-occurrence of foetal type 2 signalling? The MeDALL hypothesis. Allergy 2015; 70: 1062-78.

4. Bird JA, Stephanie L, Groetch M, et al. Conducting an oral food challenge: an update to the 2009 Adverse Reactions to Foods Committee Work Group Report. J Allergy Clin Immunol Practice 2020; 8: 75-90.

5. Samoliński B, Rapiejko P, Krzych-Fałta E, et al. Standardy wykonywania donosowych prób prowokacyjnych. Adv Dermatol Allergol 2010; 27: 141-60.

6. Augé J, Vent J, Agache I, et al. EAACI Position paper on the standardization of nasal allergen challenges. Allergy 2018; 73: 1597-608.

7. Riechelmann H, Epple B, Gropper G, et al. Comparison of conjunctival and nasal provocation test in allergic rhinitis to house dust mite. Int Arch Allergy Immunol 2003; 130: 51-9.

8. Pepper AN, Ledford DK. Nasal and ocular challenges. J Allergy Clin Immunol 2018; 141: 1570-7.

9. Samoliński B, Rapiejko P. Odpowiedź wczesna po donosowej próbie prowokacyjnej z alergenem. Adv Dermatol Allergo 2010; 27: 170-2.
10. Samoliński B, Rapiejko P. Odpowiedź późna po donosowej próbie prowokacyjnej z alergenem. Adv Dermatol Allergol 2010; 27: 173-6.

11. Abelson MB, Chambers W, Smith LM, et al. Conjunctival allergen challenge. A clinical approach to studying allergic conjunctivitis. Arch Ophthalmol 1990; 108: 84-8.

12. Fauquert JL, Jędrzejczak-Czechowicz M, Rondon C, et al. Conjunctival allergen provocation test: guidelines for daily practice. Position Paper. Allergy 2017; 72: 43-54.

13. Lindvik H, Lødrup Carlsen KC, Mowinckel P, et al. Conjunctival provocation test in diagnosis of peanut allergy in children. Clin Exp Allergy 2017; 47: 785-94.

14. Kvenshagen KB, Jacobsen M, Halvorsen R. Can conjunctival provocation test facilitate the diagnosis of food allergy in children? Allergol Immunopathol 2010; 38: 321-6.

15. Fischer R, Mcghee Jerry R, Huong Lan V, et al. Oral and nasal sensitization promote distinct immune responses and lung reactivity in a mouse model of peanut allergy. Am J Pathol 2005; 167: 1621-63.

16. Clark A, Mangat J, Tay S, et al. Facial thermography is a sensitive and specific method for assessing food challenge outcome. Allergy 2007; 62 suppl. 83: 345-9.

17. Clark A, Mangat J, King Y, et al. Thermographic imaging during nasal peanut challenge may be useful in the diagnosis of peanut allergy. Allergy 2012; 67: 574-6. 